\title{
Climatic Variability and Linear Trend Models for the Five Major Cities of Pakistan
}

\author{
Naeem Sadiq \\ Institute of Meteorology and Geophysics, Pakistan Meteorological Department \\ Met Complex, Block No. 5, Gulistan-e- Jouhar, Karachi, 75270, Pakistan \\ Tel: 92-021-996-1409 E-mail: naeemimg@yahoo.com \\ Muhammad Shahid Qureshi (Corresponding author) \\ Institute of Space and Planetary Astrophysics, University of Karachi \\ Main University Road, Karachi, 75270, Pakistan \\ Tel: 92-300-251-2627Ｅ-mail: shahidq@yahoo.com
}

\begin{abstract}
Estimates show that the average temperature of Earth's near surface air and oceans has raised by $0.74 \pm 0.18^{0} \mathrm{C}$ during last 100 years. In this work the impact of the same has been explored for major urban areas of Pakistan. For this exploration long-term mean, mean-maximum and mean-minimum temperatures for the period 1961 to 2007 have been studied. The precipitation in the major cities of Pakistan, are also studied. The maximum increase in mean temperature is found to be $0.057^{\circ} \mathrm{C}$ per year (in Quetta). The minimum increase is found to be $0.019^{\circ} \mathrm{C}$ per year (in Peshawar). Both these increments are more than the global mean. An isolated discrepancy is found in mean maximum temperature of Lahore but the same can be explained in terms of heavy and prolonged monsoon rains. Moreover, precipitation in Karachi is found to be decreasing that needs to be further explored.
\end{abstract}

Keywords: Linear and Quadratic Trend, MAPE, MAD, RMSD, Temperature, Precipitation

\section{Introduction}

In recent times, climate of the earth is more fluctuating than it was in the remote past. Particularly, the elevation of temperature of globe and shifts in time and amounts of rainfall are causing strong social and economic consequences over the globe (WMO, 2006). Human activities during the last century - particularly the burning of fossil fuels - have changed the composition of the atmosphere in ways that threaten to dramatically alter the global climate in the years to come (WMO, 2005). Rapid temperature changes affect the seasons causing variation in their duration. Changes like shorter winters can lead to mismatches between the key elements in an ecosystem, such as feeding periods for young birds and availability of worms or insects for their food. It also affects the growing seasons of farming (Pyke, 2004).

Climatic fluctuations are defined as transitory changes that can revert back after some period of time (Landsberg, 1975). However, in recent times, it is not likely to happen because the atmospheric concentration of carbon dioxide $\left(\mathrm{CO}_{2}\right)$ has now increased by 31 percent (IPCC, 2001) due to industrial revolution, population explosion, lack of plants and trees, and various entropy-disturbing phenomena. These atmospheric changes have intensified the greenhouse effect, allowing lesser sun-heat to escape the earth's atmosphere (Davies et. al., 1986). Because of the warming in the last 100 years global average temperature has increase about $0.74^{\circ} \mathrm{C}$ (IPCC, 2005). Climatic records put together with long-term records of flowering and nesting times show clear warming trends. Further cold and frost season become squeezed while hot days/nights and heat waves have become more frequent (Rohli and Viga, 2008). All these changes are happening in response to change in temperatures of just over $0.74^{\circ} \mathrm{C}$. Likewise, we are bound to see various disruptions in response to the several degrees increase, which is expected by the end of this century.

Several attempts have been made for determining precipitation and temperature trends of various parts of the globe. In the context of Australia, Hennessy et al. (1999) and Plummer et al. (1999) reported an increase in average rainfall in $20^{\text {th }}$ century. Karl et al. (1996) report similar increasing trend in daily rainfall of USA. They also describe a decline in the number of cold days and increase in the number of extremely hot days. A fine study is performed by Rao (1993) where he chalked out significant warming trend in minimum, maximum and 
mean temperatures at Mahanadi river basin, India. It has also been reported that in future the temperature will rise by several degrees along with increased precipitation (Singh, 2007). Evidences are found which reveal that Pakistan is also affected by the factors of Global warming (Sadiq, 2007); where the climate varies from temperate in the north to the hot arid tropical in the south. Annual Precipitation ranges from $2000 \mathrm{~mm}$ (approximately) in the humid north to almost none in the arid south. Thermal regimes exhibit extreme variation from over $50^{\circ} \mathrm{C}$ to several degrees below freezing point.

This work attempts to investigate the trends of two key climatic factors in the context of Pakistan, viz., (i) temperature and (ii) rainfall over five major cities, i.e., Karachi, Islamabad, Lahore, Peshawar and Quetta. To explore these trends we examined the maximum, minimum and mean temperature trends. Annual and monsoonal rainfalls are also studied using linear and quadratic models.

\section{General Climatic Features of the Region}

Some typical features considered, regarding winter, summer and monsoon seasons of the region under studied are briefly reviewed here. Winter season is considered from November to March in Pakistan. Due to high pressure system over Siberia the period is chiefly dominated by the cold air (Khan, 2003). However, Mediterranean depressions or western disturbances along their secondary lows repeatedly disturb the normal (north east to south west) isobaric pattern over Pakistan and fair to fine cool weather prevails. These disturbances in their propagation and during their passage generally bring thunderstorms and winter rains in the plains, and snow in the mountains.

April, May and June are considered as to be summer season during which the seasonal low over Balochistan (up to a height of $1.5 \mathrm{~km}$ ) appears, above which the subtropical high pressure exists (Khan, 2003). During this season Baluchistan and plains of Pakistan acquire gusty and dusty winds accompanied by dust storms due to the intense insolation. The seasonal low of Baluchistan is frequently intruded by low pressure waves moving west to east in higher latitudes in north of Pakistan. The trailing ends towards equator, of these low pressure waves successively affect mountainous north of Pakistan, causing thunderstorms and rain there.

Generally Monsoon occurs between July to September and during which the moisture laden monsoon air is injected into Pakistan, as east and/or south-east current, by monsoon depressions moving westwards through northern and central India (Khan, 2003). This monsoon air interacting with the topography and or trailing ends of eastward moving low-pressure waves produce notable rain/thundershowers. Some of these monsoon depressions reach the plains of Pakistan where they cause heavy rainfall. Thus blazing heat of summer in the plains is occasionally interrupted during July to September by spells of monsoon rains.

In the present study standard steps of estimating trend of the temperature and rainfall for the mentioned cities are followed. The main objective is to determine the climatic trend of the some major urban centers of Pakistan in order to determine the impact of global warming.

\section{Data and Methodology}

The selected data consists of different time series of mean monthly temperature and mean monthly rainfall over the period of 1961 to 2007 for the cities under study. The trend of rainfall study comprises the monsoon period and the annual rainfall pattern. Whereas the study of temperature over the indicated period considers three different time series viz., mean maximum $\left(\mathrm{T}_{\max }\right)$, mean minimum $\left(\mathrm{T}_{\min }\right)$ and mean temperatures $\left(\mathrm{T}_{\text {mean }}\right)$. The data used in the study is provided by Pakistan Meteorological Department.

We computed and analyzed the linear (2.1) and quadratic (2.4) trend models by using least square estimation.

$$
y=a x+b
$$

Where

$$
a=\frac{\sum y_{i} \cdot \sum x_{i}^{2}-\sum x_{i} \cdot \sum x_{i} y_{i}}{n \cdot \sum x_{i}^{2}-\left(\sum x_{i}\right)^{2}}
$$

And

$$
b=\frac{n \sum y_{i} \cdot x_{i}-\sum x_{i} \cdot \sum y_{i}}{n \cdot \sum x_{i}^{2}-\left(\sum x_{i}\right)^{2}}
$$


$x_{i}$ represents years in the time series considered $\left(x_{0}=0\right.$ for the year 1961, the first year in the time series considered), and $y_{i}$ represent the weather parameter considered (mean, mean maximum, mean minimum temperatures or the annual or monsoon precipitation). All summations run through $i=0,1,2, \ldots . ., 46$, i.e. a total of 47 years. (2.2) and (2.3) are the solutions to the normal equations associated with the system.

And

$$
y=a x^{2}+b x+c
$$

Where $\mathrm{a}, \mathrm{b}$ and $\mathrm{c}$ are again the solutions to the normal equations associated with the system. The linear fit, thus obtained determines the behavior of the concerned climatic factors over the indicated period. The quality of the fit is further analyzed with the help of some statistical parameters in time series for each case. These include Mean Absolute Percentage Error, (MAPE) which measures the accuracy of fitted time series values. It expresses accuracy as a percentage computed using:

$$
M A P E=\frac{\sum_{t=1}^{n}\left|\left(y_{t}-\hat{y}_{t}\right) / y_{t}\right|}{n}
$$

where $y_{\mathrm{t}}$ equals the actual values, $\hat{y}_{t}$ equals the values forecast by the models $(2.1$ or 2.4$)$ and $n$ equals the number of data values considered (47 in this study). Another parameter explored is Mean Absolute Deviation, (MAD) which measures the accuracy of fitted time series values. It expresses accuracy in the same units as the data, which helps conceptualize the amount of error. It is computed using:

$$
M A D=\frac{\sum_{t=1}^{n}\left|y_{t}-\hat{y}_{t}\right|}{n}
$$

The third parameter considered is Root Mean Squared Deviation (RMSD), a commonly-used measure of accuracy of fitted time series values. As RMSD is always computed using the same denominator, $n$, regardless of the model, you can compare RMSD values across models. RMSD is computed using:

$$
R M S D=\sqrt{\frac{\sum_{t=1}^{n}\left(y_{t}-\hat{y}_{t}\right)^{2}}{n}}
$$

The trend analysis for the temperature is presented on linear least square estimates whereas that for rain is done both linearly and quadratically.

\section{Results}

The temperature, as it is imperative from current studies, is increasing. The mean $\left(\mathrm{T}_{\text {mean }}\right)$, mean minimum $\left(\mathrm{T}_{\text {min }}\right)$ and mean maximum $\left(\mathrm{T}_{\max }\right)$ temperatures follow an increasing trend that signifies the impact of global warming over Pakistan. The results of linear trends thus obtained, are summarized in Table 1 and main features are discussed below:

The rate of increase in the minimum temperature of Quetta leads the rest, having a value $0.075^{\circ} \mathrm{C}$ per year (fig. 21a). The maximum temperature of Peshawar shows least increment among all i.e. $0.018^{\circ} \mathrm{C}$ per year. Most of the temperatures of considered cities have rates of increase that lie within $0.02^{\circ} \mathrm{C}$ to $0.04^{\circ} \mathrm{C}$ per year. The mean temperature of Quetta and the minimum temperature of Lahore have almost same rate, as it is evident from Table 1. The only deviation from the general warming is shown by the maximum temperature of Lahore that has a negative slope $\left(-0.004^{\circ} \mathrm{C} /\right.$ year $)$, that appears as an outlier. However, an in depth analysis of the trends of rainfall indicates that Lahore received heavy and prolonged monsoon precipitation during a number of years during the period of study, especially during the mid nineties. This may be one of the possible reasons for an overall small decrease in the mean maximum temperature. However, the mean and the mean minimum are also found to show an increasing trend with rates $0.025^{\circ} \mathrm{C}$ and $0.054^{\circ} \mathrm{C}$ per year respectively. The quadratic trend analysis was also attempted; however, the same shows no significant improvement in the results and the linear trend analysis is 
found to be sufficient to extract the general rising tendency of temperatures. For this reason the results are not reported.

It is generally anticipated that the consequence of global warming is an increase in precipitation in South Asia. The results obtained in this work also conform to this notion and all the cities show rise in annual precipitation except Karachi. The yearly and monsoonal trends for Karachi appear to be similar (Fig. 7 and 8) as the major share of total precipitation of the city lies in the monsoonal months indicated in Fig. 6. The decrease of $2.07 \mathrm{~mm}$ (fig. 21b) rainfall per year in Karachi is a notable feature that may be caused by other latent factors that need to be explored. Apart from linear trend analysis the quadratic least square estimates have also been studied in order to obtain relatively more convergent results. The results of quadratic fitting are still found to be marginally better than the linear trend analysis as indicated by Table 2 .

The monsoonal impacts over Lahore and Islamabad are more pronounced in comparison to other cities (fig 9 \& 18). Both these cities received most of the rains in monsoonal season indicating August and July as the peak months for Islamabad and Lahore respectively. It is because of the monsoonal depressions which are the main contributors to the annual rainfall in the plains of Punjab (Khan J. A., 1993). The histograms in Fig. 9 and 18 also exhibit comparably less rains over these regions other than during the monsoon.

The annual precipitation of Peshawar discloses that the city is more influenced by winter than the monsoon rainfall since sub-mountainous Punjab and NWFP receive nearly equal share of winter and summer rainfall as showed in Fig. 12, 13 and 14. Rainfall decreases from west to east in winter and vice versa in summer.

Although Quetta receives its major share of precipitation during the winters (Fig 13) but its monsoonal trend shows an increase of $0.25 \mathrm{~mm} /$ year (fig 14) that is less than yearly increment (fig 15), which is $0.556 \mathrm{~mm} /$ year (Table 2).

\section{Discussion and Future Outlook}

Climate assessment essentially involves a good understanding of rainfall and temperature patterns. As such, there are many factors to be considered while studying climate. Our results of linear behavior of increase in temperature in cities except Lahore (Fig. 18) show that the effects of global warming are clear in these cities (Table 1). It follows from the above calculations that the considered urban areas of Pakistan, as in many developed and developing countries are facing land-ocean-atmosphere problems caused by warming of globe. The rainfall of Karachi shows negative slope, as it is evident from Fig. 7 and 8. The rainfall pattern is difficult to be determined using linear trend analysis, as seen from the values of MAPE, MAD and RMSD. We employed quadratic trend analysis that yields slightly better results. The comparison of both techniques is given in Table 2 .

Scientific evidences are piling up day by day, showing the effects of global warming on the rainfall (Sadiq 2007, Iqbal J. 2005, Usmani B A, 2008). The rainfall of the main urban cities of Pakistan follow highly non-linear pattern and employing a more sophisticated technique, as ARIMA modeling and Neural Network to detect the trend of the region should be taken in to account. Moreover the nonlinearities within the data can be dealt by using windowing and space-time separation plots' techniques. An interesting open question is to model $\mathrm{T}_{\max }$ of Lahore and Annual and Monsoon rainfall patterns of Karachi to identify and explain its unexpected behavior in contrast to other cities of Pakistan.

\section{References}

Davies, T. D., Kelly, P. M., Brimblecombe, P., Farmer, G., and Barthelmie, R. J. (1986). Acidity of Scottish rainfall influenced by climatic change. Nature, 322, 359-361.

Hennessy, K. J., Suppiah, R., and Page, C. M. (1999). Australian rainfall changes, 1910-1995. Australian Meteorological Magazine, 48, 1-13.

IPCC. (2001). Climate Change 2001: The Scientific Basis. Cambridge University Press, New York, 881pp.

IPCC. (2007). Climate Change 2007: The Physical Science Basis. Cambridge University Press, New York, 996 pp.

Iqbal, M. J. (2005). Detection and modeling of hydro-meteorological variability over Pakistan region, Ph.D Thesis, University of Karachi.

Karl, T., Knight, R., Easterling, D., and Quayle, R. (1996). Indices of climate change for the United Sates. Bulletin. American Meteorological Society, 77, 279-291.

Khan, J. A. (2003). Interpretation of Weather Maps. Pakistan Geographical Association, Karachi, 46 pp.

Khan, J. A. (1993). The Climate of Pakistan. Rehbar Publishers, Karachi, 79 pp. 
Landsberg, H. E. (1975). Sahel drought change of climate or part of climate. Arch. Met. Geophy. Bioklim. Scr. B. 23: 193-200.

Plummer, N., Salinger, M. J., Nicholls, N., Suppiah, R., Hennessy, K. J., Leighton, R. M., Trewin, B., Page, C. M., \& Lough, J. M. (1999). Changes in climate extremes over the Australian region and New Zealand during the twentieth century. Climatic Change, 42, 183-202.

Pyke, C. (2004). Habitat loss confounds climate change impacts. Frontiers in Ecology and the Environment, 2 (4), 178-182.

Rao, P. G. (1993). Climate changes and trends over a major river basin in India. Climate Research, 2, 215-223.

Rohli, R. V. and Vega., A. J. (2008). Climatology. Jones and Bartlett Publishers, USA, 466 pp.

Sadiq, N. (2007). Classification of weather at Karachi region. M. Phil. Thesis, University of Karachi.

Singh, C. (2007). Global Warming and Climatology. Akansha publishing House, New Delhi, 318 pp.

Usmani, B. A. (2008). Modeling monsoon rainfall data of North-Eastern part of Pakistan region. M. Phil. Thesis, University of Karachi.

WMO Bulletin. (2005). The Global Climate System in 2004: WMO annual statement on the status of the global climate. WMO, Geneva, 54 (2), 87-91.

WMO Bulletin. (2006). The Global Climate System in 2005: WMO annual statement on the status of the global climate. WMO, Geneva, 55 (2), 129-133.

Table 1. Linear Trend equations of mean, maximum and minimum temperatures along MAPE, MAD and RMSD values for the major cities of Pakistan

\begin{tabular}{|c|c|c|c|c|c|}
\hline City & Temp & Linear Trend & MAPE & MAD & RMSD \\
\hline \multirow{3}{*}{ Karachi } & Mean & $y_{t}=0.0324 t+25.586$ & 1.112 & 0.294 & 0.372 \\
\hline & $\operatorname{Max}$ & $y_{\mathrm{t}}=0.0255 \mathrm{t}+31.38$ & 0.902 & 0.289 & 0.374 \\
\hline & Min & $y_{t}=0.0379 t+19.852$ & 2.053 & 0.426 & 0.542 \\
\hline \multirow{3}{*}{ Lahore } & Mean & $y_{t}=0.0249 t+23.957$ & 1.375 & 0.336 & 0.430 \\
\hline & $\operatorname{Max}$ & $y_{\mathrm{t}}=-0.0042 \mathrm{t}+30.823$ & 1.357 & 0.414 & 0.572 \\
\hline & Min & $y_{\mathrm{t}}=0.0543 \mathrm{t}+17.073$ & 2.067 & 0.378 & 0.430 \\
\hline \multirow{3}{*}{ Peshawar } & Mean & $y_{\mathrm{t}}=0.0191 \mathrm{t}+22.342$ & 1.736 & 0.396 & 0.471 \\
\hline & $\operatorname{Max}$ & $y_{\mathrm{t}}=0.0182 \mathrm{t}+29.108$ & 1.702 & 0.502 & 0.607 \\
\hline & Min & $y_{t}=0.0209 t+15.566$ & 3.039 & 0.489 & 0.573 \\
\hline \multirow{3}{*}{ Quetta } & Mean & $y_{\mathrm{t}}=0.0574 \mathrm{t}+14.859$ & 3.145 & 0.504 & 0.616 \\
\hline & $\operatorname{Max}$ & $y_{\mathrm{t}}=0.0343 \mathrm{t}+23.92$ & 2.685 & 0.663 & 0.820 \\
\hline & Min & $y_{\mathrm{t}}=0.0751 \mathrm{t}+5.8777$ & 6.442 & 0.473 & 0.638 \\
\hline \multirow{3}{*}{ Islamabad } & Mean & $y_{\mathrm{t}}=0.0252 \mathrm{t}+20.977$ & 1.747 & 0.377 & 0.471 \\
\hline & $\operatorname{Max}$ & $y_{\mathrm{t}}=0.0211 \mathrm{t}+28.184$ & 1.799 & 0.515 & 0.657 \\
\hline & Min & $y_{t}=0.0306 t+13.705$ & 2.797 & 0.402 & 0.497 \\
\hline
\end{tabular}


Table 2. Linear and Quadratic Trend equations of monsoonal and yearly rainfall along MAPE, MAD and RMSD values for the major cities of Pakistan

\begin{tabular}{|c|c|c|c|c|c|}
\hline City & Rainfall & Linear \& Quadratic Trend & MAPE & MAD & RMSD \\
\hline \multirow{4}{*}{ Karachi } & \multirow{2}{*}{ Monson } & $y_{\mathrm{t}}=-2.3191 \mathrm{t}+206.7$ & 85.09 & 121.32 & 143.9 \\
\hline & & $y_{\mathrm{t}}=0.087 \mathrm{t}^{2}-6.3221 \mathrm{t}+236.72$ & 79.43 & 121.33 & 143.19 \\
\hline & \multirow{2}{*}{ Yearly } & $y_{t}=-2.0733 t+247.66$ & 43.27 & 135.65 & 167.77 \\
\hline & & $y_{t}=0.1117 t^{2}-7.2109 t+286.19$ & 39.11 & 134.57 & 176.76 \\
\hline \multirow{4}{*}{ Lahore } & \multirow{2}{*}{ Monson } & $y_{\mathrm{t}}=1.1617 \mathrm{t}+398.46$ & 37.08 & 141.19 & 181.77 \\
\hline & & $y_{t}=-0.2783 t^{2}+13.965 t+302.44$ & 36.44 & 140.16 & 179.54 \\
\hline & \multirow{2}{*}{ Yearly } & $y_{\mathrm{t}}=3.0351 \mathrm{t}+563.27$ & 29.61 & 171.91 & 215.73 \\
\hline & & $y_{t}=-0.3475 t^{2}+19.018 t+443.4$ & 29.09 & 170.1 & 210 \\
\hline \multirow{4}{*}{ Peshawar } & \multirow{2}{*}{ Monson } & $y_{\mathrm{t}}=1.1384 \mathrm{t}+108.36$ & 116.7 & 65.56 & 85.79 \\
\hline & & $y_{\mathrm{t}}=-0.0617 \mathrm{t}^{2}+3.9786 \mathrm{t}+87.064$ & 115.1 & 66.42 & 85.19 \\
\hline & \multirow{2}{*}{ Yearly } & $y_{\mathrm{t}}=3.4958 \mathrm{t}+362.02$ & 47.62 & 106.72 & 142.46 \\
\hline & & $y_{\mathrm{t}}=0.0904 \mathrm{t}^{2}-0.6607 \mathrm{t}+393.2$ & 47.13 & 104.77 & 141.64 \\
\hline \multirow{4}{*}{ Quetta } & \multirow{2}{*}{ Monson } & $y_{\mathrm{t}}=0.2594 \mathrm{t}+19.228$ & 76.36 & 28.87 & 41.22 \\
\hline & & $y_{\mathrm{t}}=-0.0686 \mathrm{t}^{2}+3.3457 \mathrm{t}-3.4048$ & 72.93 & 28.15 & 39.78 \\
\hline & \multirow{2}{*}{ Yearly } & $y_{\mathrm{t}}=0.5565 \mathrm{t}+239.53$ & 55.61 & 91.01 & 147.5 \\
\hline & & $y_{\mathrm{t}}=-0.363 \mathrm{t}^{2}+16.89 \mathrm{t}+119.75$ & 68.52 & 88.21 & 137.44 \\
\hline \multirow{4}{*}{ Islamabad } & \multirow{2}{*}{ Monson } & $y_{\mathrm{t}}=5.7119 \mathrm{t}+589.16$ & 32.52 & 173.79 & 220.53 \\
\hline & & $y_{\mathrm{t}}=-0.2173 \mathrm{t}^{2}+15.708 \mathrm{t}+514.2$ & 33.02 & 175.32 & 217.43 \\
\hline & \multirow{2}{*}{ Yearly } & $y_{\mathrm{t}}=7.2594 \mathrm{t}+1021.6$ & 19.25 & 210.1 & 261.5 \\
\hline & & $y_{\mathrm{t}}=-0.295 \mathrm{t}^{2}+20.832 \mathrm{t}+919.77$ & 18.98 & 211.9 & 255.25 \\
\hline
\end{tabular}

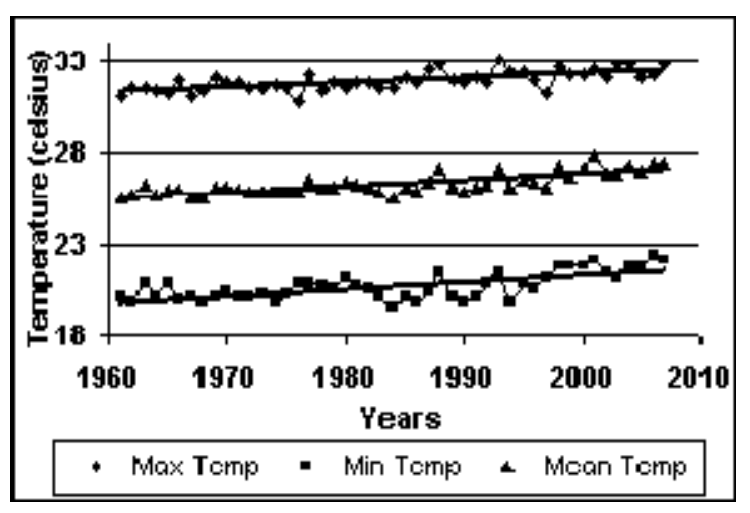

Figure 1. Tmax, Tmean, Tmin of Karachi (1961-2007)

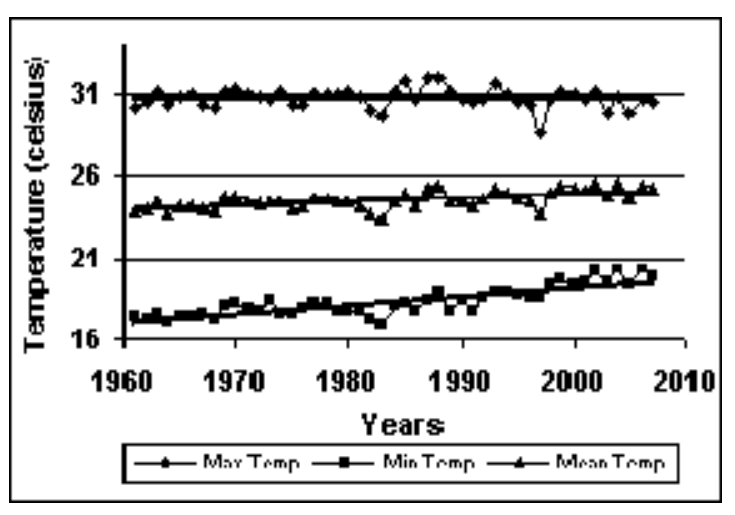

Figure 2. Tmax, Tmean, Tmin of Lahore (1961-2007) 


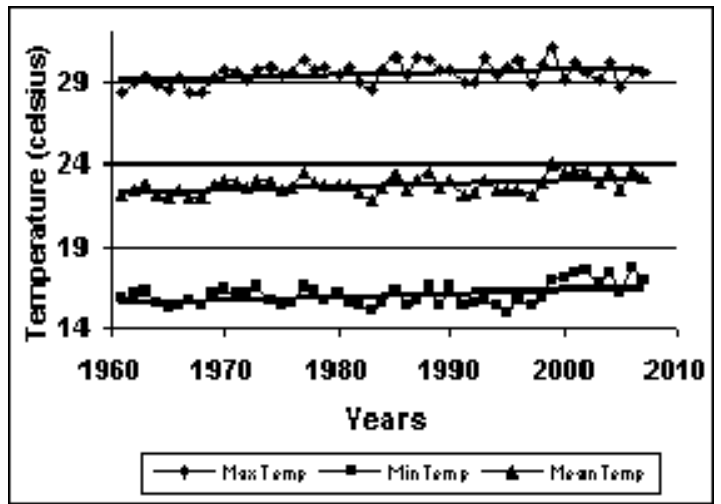

Figure 3. Tmax, Tmean, Tmin of Peshawar (1961-2007)

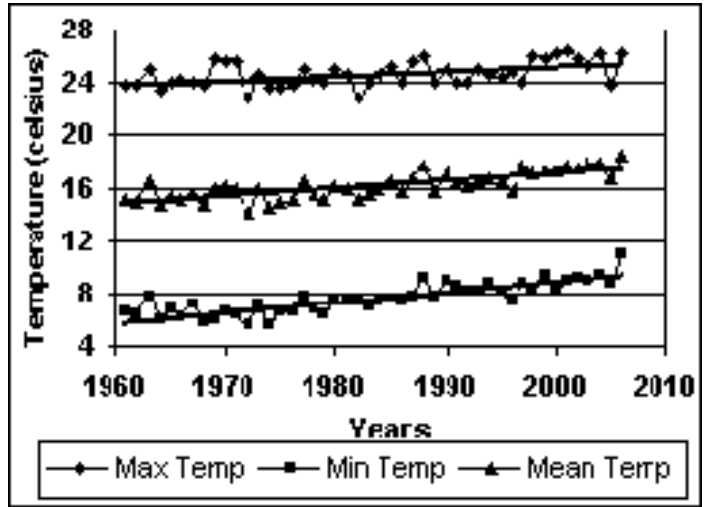

Figure 4. Tmax, Tmean, Tmin of Quetta (1961-2007)

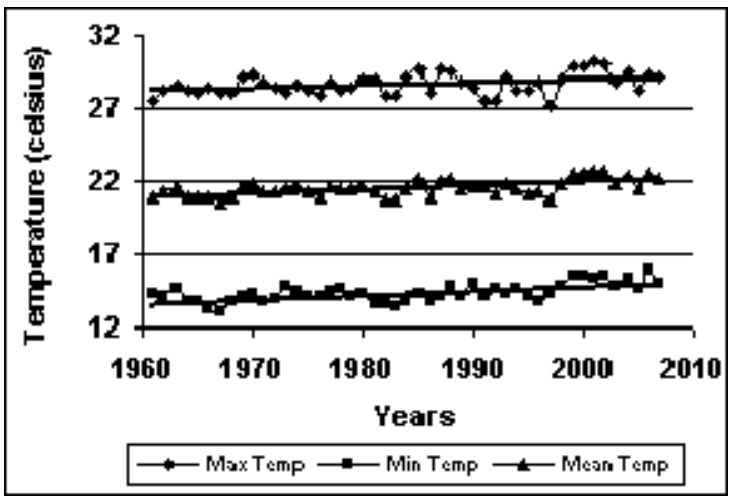

Figure 5. Tmax, Tmean, Tmin of Islamabad (1961-2007)

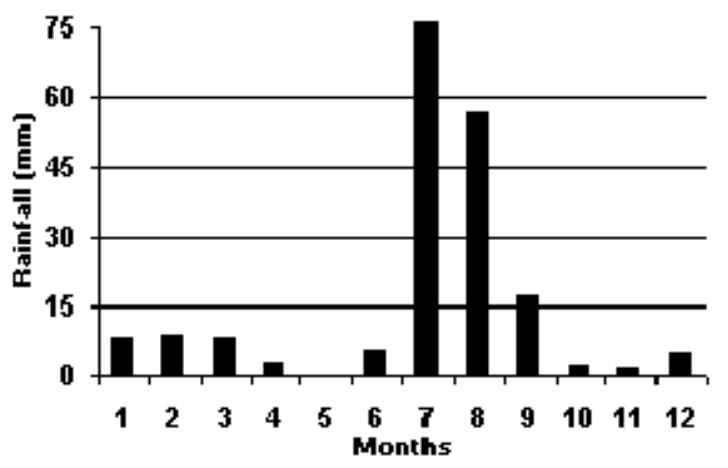

Figure 6. Annual rainfall frequency for Karachi

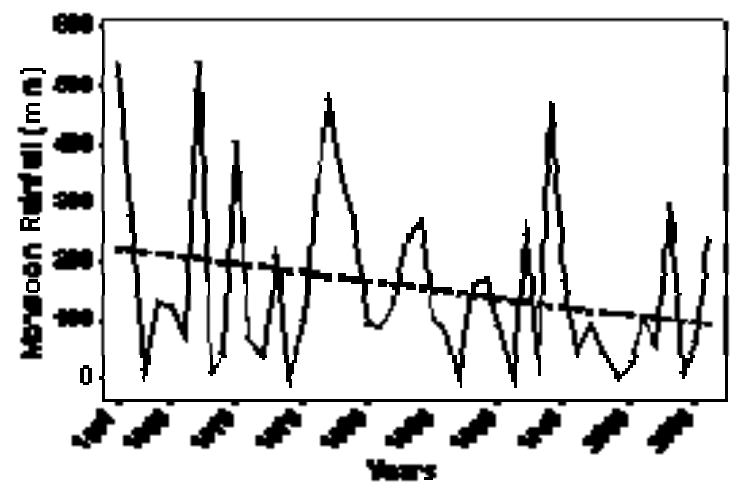

Figure 7. Linear Trend Model for Karachi Monsoon 


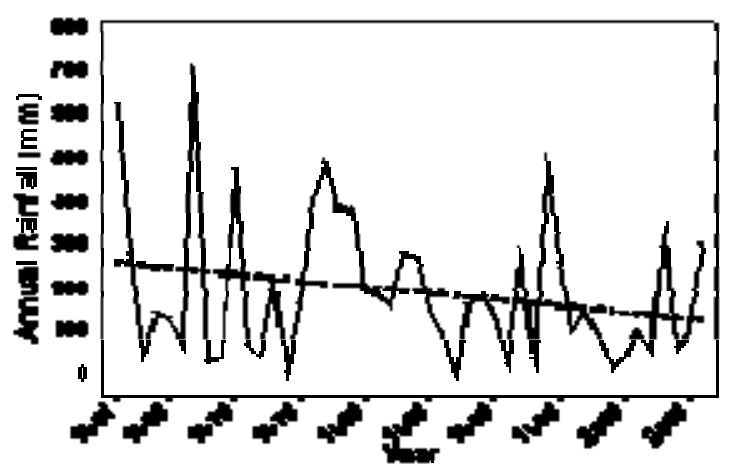

Figure 8. Yearly Linear Trend Model for Karachi

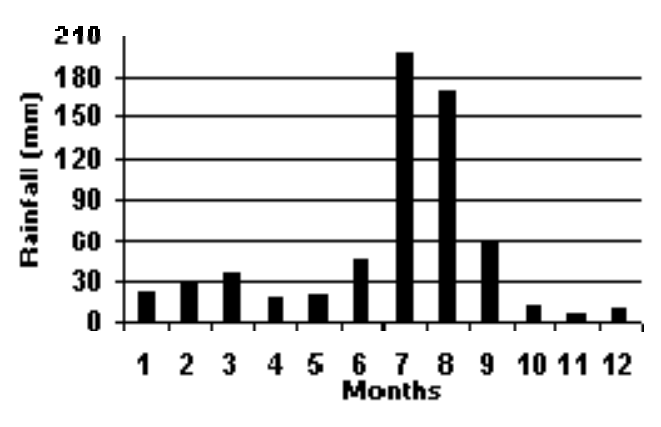

Figure 9. Annual rainfall frequency for Lahore

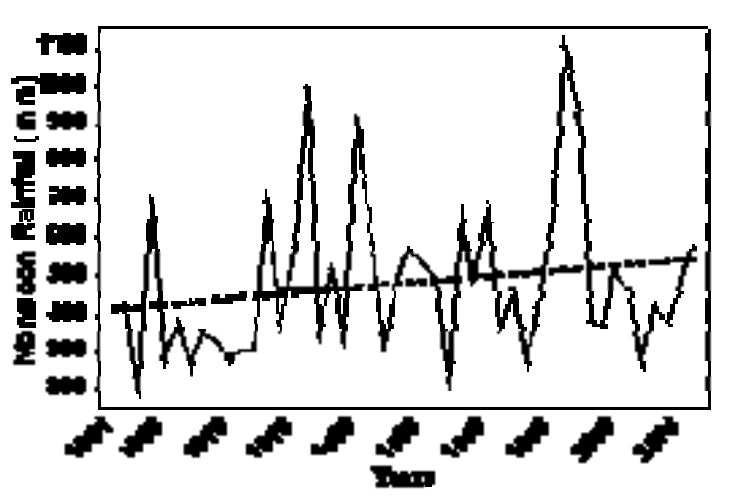

Figure 10. Linear Trend Model for Lahore Monsoon

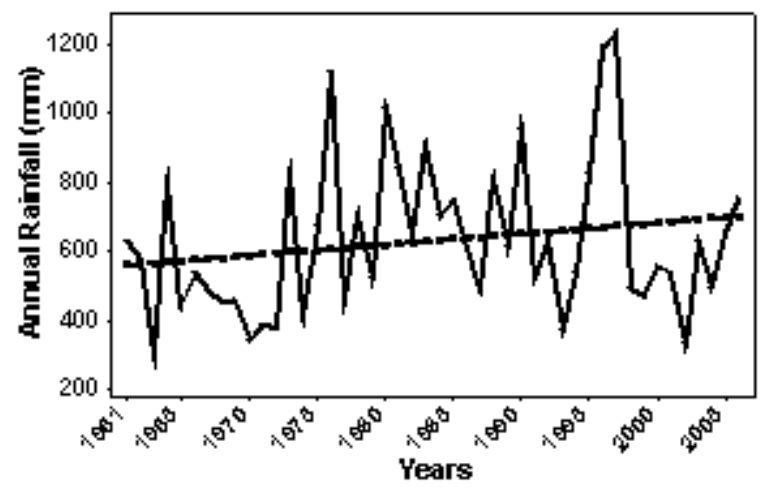

Figure 11. Yearly Linear Trend Model for Lahore

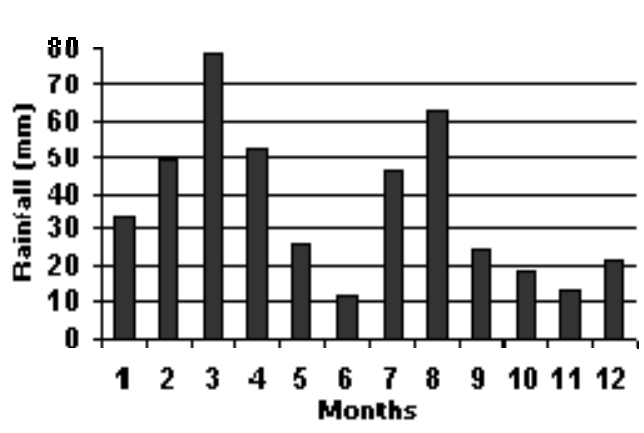

Figure 12. Annual rainfall frequency for Peshawar

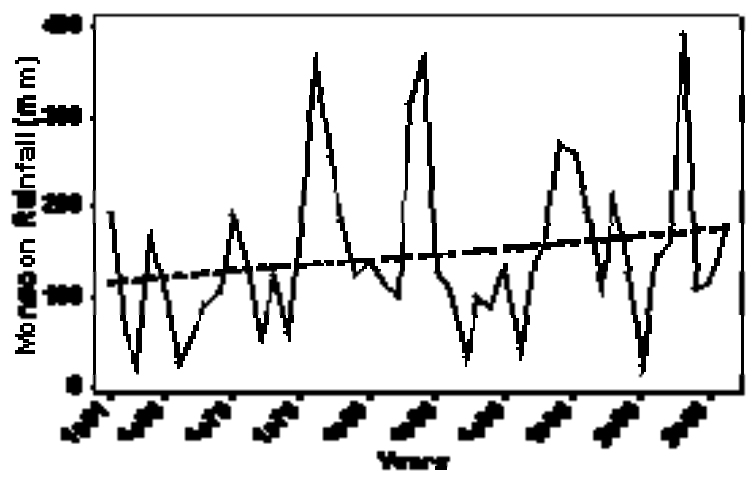

Figure 13. Linear Trend Model for Peshawar Monsoon 


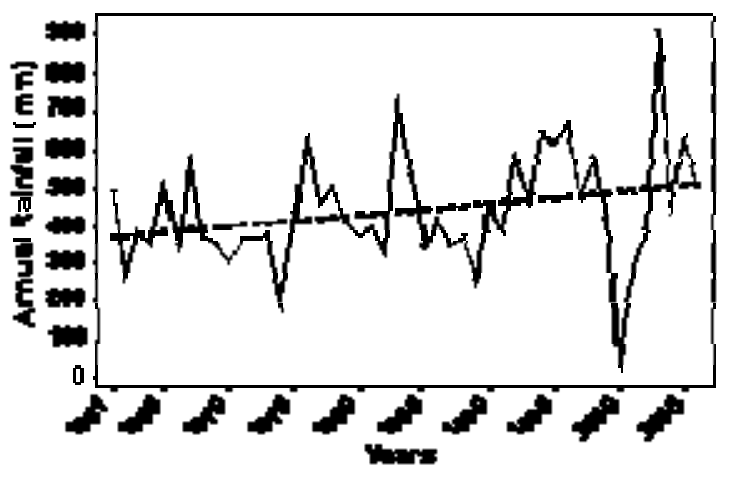

Figure 14. Yearly Linear Trend Model for Peshawar

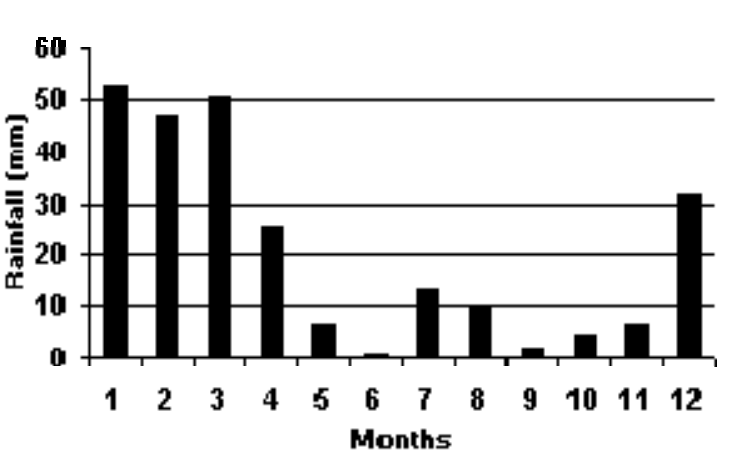

Figure 15. Annual rainfall frequency for Quetta

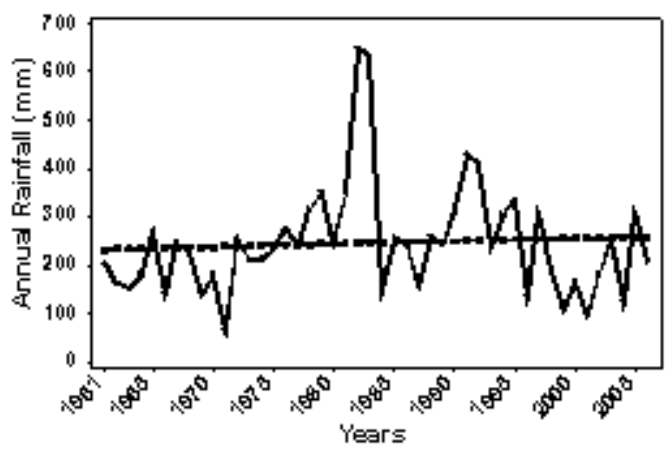

Figure 17. Yearly Linear Trend Model for Quetta

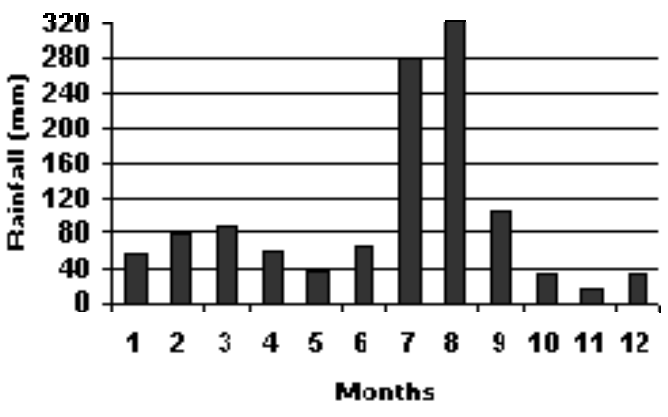

Figure 18. Annual rainfall frequency for Islamabad

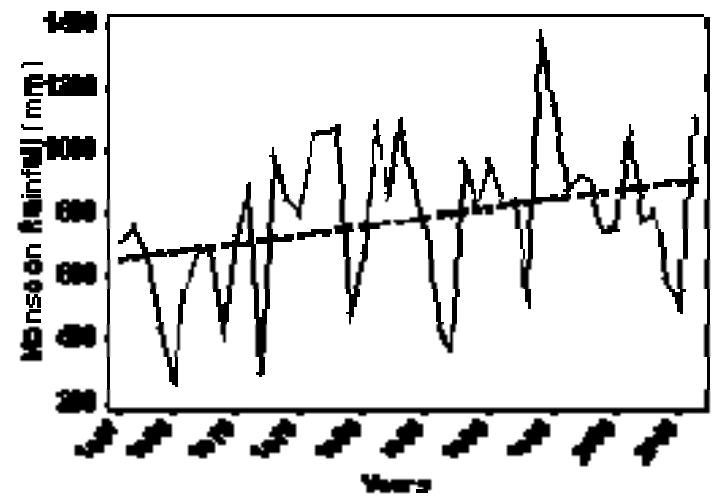

Figure 19. Linear Trend Model for Islamabad monsoon 


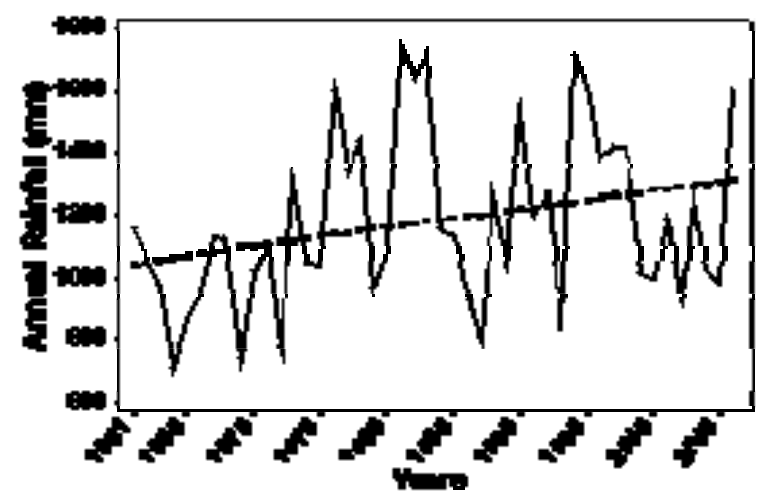

Figure 20. Yearly Linear Trend Model for Islamabad

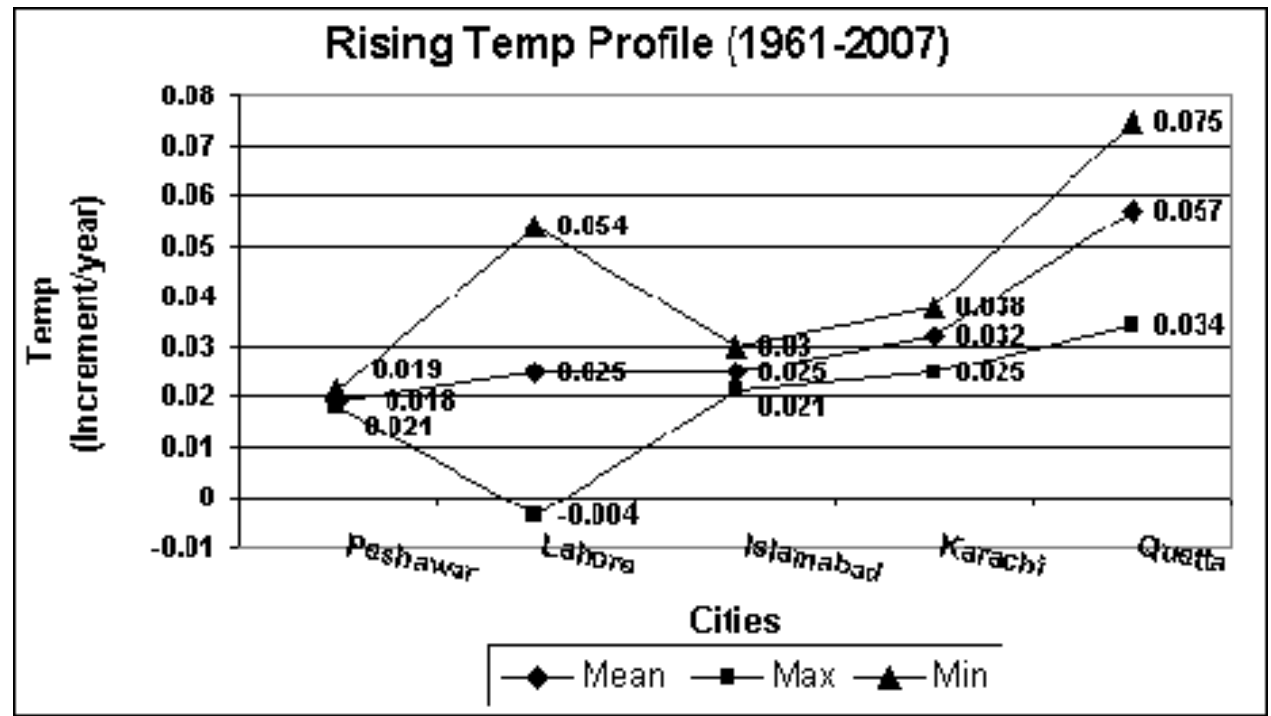

Figure 21(a). Temperature increment per annum for considered cities

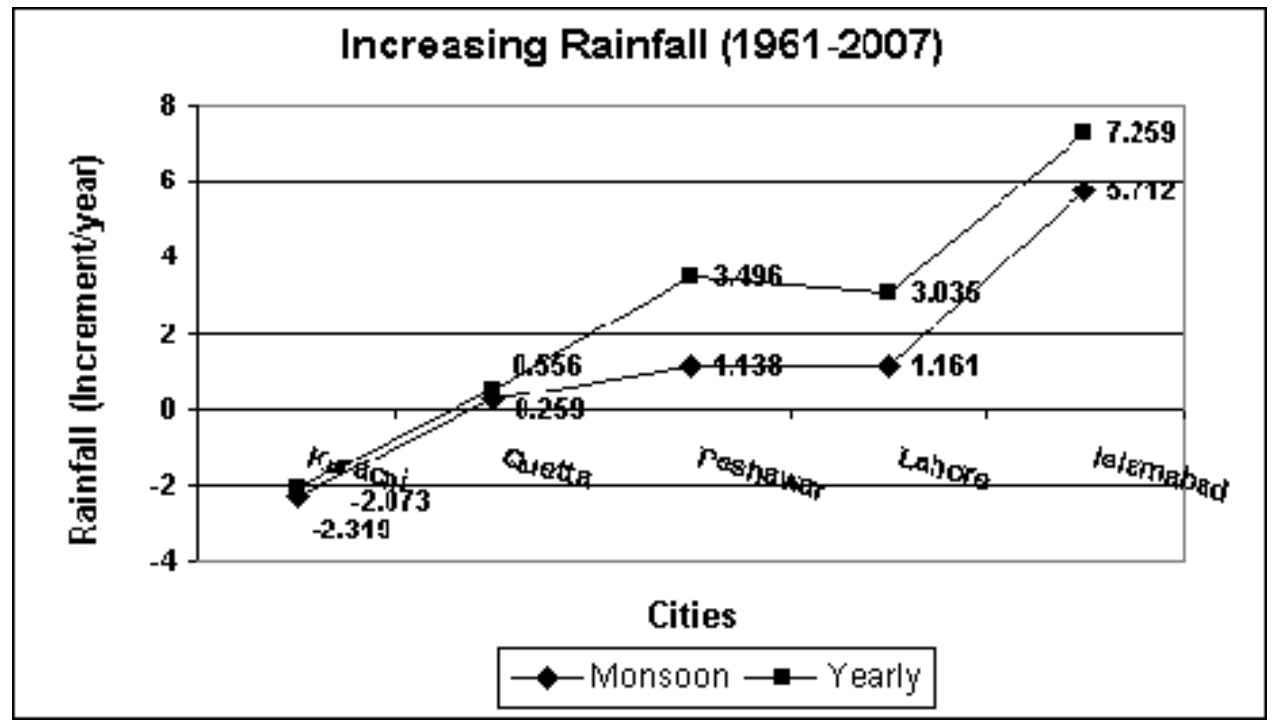

Figure 21(b). Rainfall increment per annum for considered cities 